\title{
Effect of fixed orthodontic appliances on salivary microbial parameters at 6 months: a controlled observational study
}

\author{
Delphine MARET ${ }^{1}$, Christine MARCHAL-SIXOU ${ }^{2}$, Jean-NoëI VERGNES ${ }^{3}$, Olivier HAMEL ${ }^{3}$, Marie GEORGELIN-GURGEL ${ }^{1}$, \\ Lucas VAN DER SLUIS ${ }^{4}$, Michel SIXOU ${ }^{3}$
}

\author{
1- Department of Conservative Dentistry and Endodontics, Faculté de Chirurgie Dentaire, Université Paul Sabatier, Centre Hospitalier Universitaire, Toulouse, \\ France. \\ 2- Department of Orthodontics, Faculté de Chirurgie Dentaire, Université Paul Sabatier, Centre Hospitalier Universitaire; Laboratoire Universitaire LU 51: \\ Maladies parodontales, déséquilibres systémiques et biomatériaux (MPDSB), Université Paul Sabatier, Toulouse, France. \\ 3- Department of Public Health, Faculté de Chirurgie Dentaire, Université Paul Sabatier, Centre Hospitalier Universitaire; Laboratoire Universitaire LU 51: \\ Maladies parodontales, déséquilibres systémiques et biomatériaux (MPDSB), Université Paul Sabatier, Toulouse, France. \\ 4- Department of Conservative Dentistry and Pedodontology, Center of Dentistry and Oral Health, UMCG Groningen, Groningen, the Netherlands.
}

Corresponding address: Delphine Maret - Faculté de Chirurgie Dentaire - Université Paul Sabatier - Centre Hospitalier Universitaire - 3 chemin des Maraîchers 31062 - Toulouse - France - e-mail: delphine_maret@yahoo.fr

Submitted: May 15, 2013 - Modification: August 31, 2013 - Accepted: September 26, 2013

\section{ABSTRACT}

\begin{abstract}
bjective: The aim of this study was to assess the microbial changes in children with fixed orthodontic appliances compared with a control group of children without orthodontic treatment. Material and Methods: Ninety-five children, aged between 12 and 16 years, participated in this study. Forty-eight subjects were fitted with fixed orthodontic appliances and forty-seven were free of any such appliances. The follow-up was 6 months for all children. The association between orthodontic appliances and high levels of Streptococcus mutans and Lactobacillus spp was assessed with logistic regression models, taking age, sex, pH and buffer capacity into account. Results: Differences at baseline between the two groups were not statistically significant. We found that wearing a fixed orthodontic appliance was associated with high levels of Streptococcus mutans and Lactobacillus spp (adjusted OR: $6.65,95 \%$ CI [1.98-22.37]; 9.49, 95\% CI [2.57-35.07], respectively), independently of other variables. Conclusion: The originality of the present epidemiological study was to evaluate the evolution of salivary microbial parameters in a population of children with fixed orthodontic appliances. Our results show an increase of Streptococcus mutans and Lactobacillus spp values during the follow-up. The whole dental workforce should be aware that preventive measures are of paramount importance during orthodontic treatment.
\end{abstract}

Keywords: Orthodontic appliances. Streptococcus mutans. Lactobacillus.

\section{INTRODUCTION}

Orthodontic treatment consists of the placing of orthodontic appliances to correct the bite 22 and thus achieve long-lasting balanced occlusion. The prevalence of orthodontic treatment in developed countries ranges from $10 \%$ to $35 \%{ }^{12}$. Fixed orthodontic appliances have been found to induce specific changes in the oral environment, such as increased plaque accumulation ${ }^{5}$, raised Streptococcus mutans colonization $8,18,23,26$, and increases in Lactobacillus $\mathrm{spp}^{24}$, which are closely associated with dental caries $^{29}$. The $\mathrm{pH}$ of saliva and its buffer capacity contribute to its ability to counter the acid produced locally in the oral cavity? Some studies investigating interactions between orthodontic material, microorganisms, and saliva have not detected specific associations between orthodontic appliances and clinical or microbial outcomes ${ }^{1,4,10,11}$ whereas others have ${ }^{7,15,21,25}$. Peros, et al. ${ }^{21}$ (2011) presented new data on the salivary microbial changes with time caused by the placement of fixed orthodontic appliances. As in some other investigations ${ }^{7,15}$, a significant increase in Streptococcus mutans and Lactobacillus spp in saliva was found after the start of fixed orthodontic 
therapy. However, the first significant increase was only detected 6 weeks after the fixed orthodontic appliances were placed, and the highest levels were registered at the $12^{\text {th }}$ week of therapy.

To evaluate the oral changes with orthodontic appliances, studies have used a variety of methodology designs. The way salivary parameters are investigated also varies from study to study. Some authors compare the salivary parameters between two groups (orthodontic and control groups) ${ }^{15}$, others compare parameters over time in an orthodontic group without a control group 21,25 . Time of follow-up also varies across studies $7,21,25$.

The aim of this study was to assess the microbial changes in children with fixed orthodontic appliances compared with a control group of children without orthodontic treatment, over a period of six months.

\section{MATERIAL AND METHODS}

\section{Study population}

The study population consisted of two groups of children aged between 12 and 16 years. Subjects were all living in the same area (two departements of the Midi-Pyrenees region of France). The first group was recruited in three private orthodontic practices and comprised children with a fixed appliance at baseline. The orthodontic appliances were made of metal and fixed to the vestibular surfaces of permanent teeth. All the patients were fitted with maxillary and mandibular full-mouth brackets. The control group was made up of children without orthodontic appliances, recruited in three private practices. For both groups, noninclusion criteria were history of recent treatment for systemic disease (diabetes, hyposialia or mineralization defects), antibiotic or local antiseptic therapy within the three weeks preceding the observation, untreated carious lesions, and nonerupted permanent first molars. Both groups of subjects received systematic oral hygiene instruction at the start of the study. Each patient was followed for six months.

All patients and their parents were informed of the purpose of the study. None declined to participate. The study was approved by the Ethics Committee of the Dental School of Toulouse, Paul Sabatier University, France.

\section{Data collection}

Salivary $\mathrm{pH}$, buffer capacity, Streptococcus mutans and Lactobacillus spp were recorded at 0 and 6 months. Fixed orthodontic treatment was placed at time 0 after the first samples had been taken. Subsequent sampling was performed on the scheduled date plus or minus two days.

\section{Oral health behaviour}

The record of oral health behaviour noted the frequency of daily tooth-brushing and an estimated daily frequency of sugar consumption. A sugar intake frequency of less than four times per day was used as a reference point ${ }^{3,14,20}$.

\section{Salivary microbial procedures}

Salivary microbial procedures were standardized in detail and carried out by two trained dentists. Stimulated saliva samples were obtained from the patients by asking them to chew paraffin wax until $2 \mathrm{ml}$ of saliva had been collected. The salivary $\mathrm{pH}$, buffer capacity, Streptococcus mutans and Lactobacillus spp were recorded for each sample. Levels of salivary Streptococcus mutans and Lactobacillus spp were determined using Dentocult ${ }^{\circledR}$ SM strips and the Dentocult ${ }^{\circledR}$ LB method according to the manufacturer's instructions (Orion Diagnostica ${ }^{\circledR}$, Espoo, Finland $)^{13,17}$. The number of Streptococcus mutans per $\mathrm{ml}$ of saliva was estimated by comparing the test strip with the evaluation chart provided by the manufacturer.

The number of colony-forming units (CFU) of each sample was counted and scored in either the low caries risk ( $<10^{5} \mathrm{CFU} / \mathrm{ml}$ of saliva) or high caries risk ( $\geq 10^{5} \mathrm{CFU} / \mathrm{ml}$ of saliva) category by comparing the Streptococcus mutans colony density with the manufacturer's samples: low risk $=$ manufacturer's classes $1\left(10^{3} \mathrm{CFU} / \mathrm{ml}\right)$ and 2 $\left(10^{4} \mathrm{CFU} / \mathrm{ml}\right)$, high risk $=$ classes $3\left(10^{5} \mathrm{CFU} / \mathrm{ml}\right)$ and $4\left(10^{6} \mathrm{CFU} / \mathrm{ml}\right)^{13}$. A similar method was used for Lactobacillus spp categories: low caries risk (classes 1 and 2), high caries risk (classes 3 and $4)^{17}$. Dentobuff ${ }^{\circledR}$ Strip (Orion Diagnostica ${ }^{\circledR}$, Espoo, Finland) was used to estimate the salivary buffer capacity $^{9}$. For the measurement of the buffer capacity, $3 \mathrm{ml}$ of $0.005 \mathrm{~N}$ hydrochloric acid was added to a test tube containing $1 \mathrm{ml}$ saliva and shaken immediately. After 5 minutes, the colour of the strip was compared with a colour chart defining: low (final $\mathrm{pH} \leq 4.0$ ), intermediate (final $\mathrm{pH} 4.5-5.5$ ), and high (final $\mathrm{pH} \geq 6.0$ ) salivary buffer capacity ${ }^{9}$. Salivary $\mathrm{pH}$ was measured with a digital $\mathrm{pH}$-meter (Hanna Instruments ${ }^{\circledR} 8417$, USA) 30 to 60 minutes after saliva samples were collected, and $\mathrm{pH}$ was considered as a quantitative variable.

\section{Statistical analysis}

The statistical analysis was performed using the STATA 9 software package. The data were analysed using descriptive statistics. A Fisher exact test for qualitative variables and a Student test for quantitative variables were used to determine the significance of differences between the two groups at baseline. The number of subjects was calculated to have $80 \%$ power to detect at least $30 \%$ difference in occurrence of high levels of 
bacterial species between the two groups, at the 0.05 level of significance and in a bilateral situation. Anticipating a $10 \%$ rate of loss to follow-up, two groups of 46 subjects were necessary.

Two logistic regression models were applied, to assess the possible association between subjects

Table 1- Descriptive analysis of variables at baseline

\begin{tabular}{|c|c|c|c|}
\hline & Control group & Orthodontic group & pa \\
\hline & $\mathrm{n}=47$ & $\mathrm{n}=48$ & \\
\hline Streptococcus mutans levels & & & 1.00 \\
\hline Low & 37 & 37 & \\
\hline High & 10 & 11 & \\
\hline Lactobacillus spp levels & & & 0.55 \\
\hline Low & 42 & 40 & \\
\hline High & 5 & 8 & \\
\hline Salivary buffer capacity & & & 0.09 \\
\hline Low & 37 & 44 & \\
\hline High & 10 & 4 & \\
\hline $\begin{array}{l}\text { Estimated daily sugar } \\
\text { consumption }\end{array}$ & & & 1.00 \\
\hline$<4 /$ day & 34 & 34 & \\
\hline$\geq 4 /$ day & 13 & 14 & \\
\hline Daily tooth-brushing & & & 0.10 \\
\hline Yes & 24 & 33 & \\
\hline No & 23 & 15 & \\
\hline $\mathrm{pH}$ (mean +/- s.d.) & $7.37(+/-0.57)$ & $7.49(+/-0.43)$ & 0.26 \\
\hline
\end{tabular}

$\mathrm{a}$ : Two-sided Fisher's exact test for qualitative variables, Student $\mathrm{t}$ test for quantitative variable $(\mathrm{pH})$ s.d. : standard deviation

Table 2- Risk factors for high levels of Streptococcus mutans after a 6-month follow-up perioda

\begin{tabular}{|c|c|c|}
\hline & \multicolumn{2}{|c|}{ High levels of Streptococcus mutans } \\
\hline & $\mathrm{aOR}^{\mathrm{b}}$ & $95 \% \mathrm{Cl}^{\mathrm{c}}$ \\
\hline \multicolumn{3}{|c|}{ Wearing a fixed orthodontic appliance } \\
\hline Yes & 6.65 & $1.98-22.37$ \\
\hline No & 1.00 & \\
\hline Age d & 1.11 & $0.72-1.71$ \\
\hline \multicolumn{3}{|l|}{ Gender } \\
\hline Female & 1.10 & $0.38-3.19$ \\
\hline Male & 1.00 & \\
\hline \multicolumn{3}{|c|}{ Salivary buffer capacity } \\
\hline Low & 1.24 & $0.18-8.27$ \\
\hline High & 1.00 & \\
\hline $\mathrm{pH} \mathrm{d}$ & 0.87 & $0.13-5.95$ \\
\hline
\end{tabular}

a: Logistic regression model adjusted for all potential predictors reported in the table

b: Adjusted Odds Ratio

c: $95 \%$ Confidence Interval of the aOR

d: aOR per unit increase 
Table 3- Risk factors for high levels of Lactobacillus spp after a 6-month follow-up period ${ }^{\text {a }}$

\begin{tabular}{|c|c|c|}
\hline & \multicolumn{2}{|c|}{ High levels of Lactobacillus spp } \\
\hline & $\mathrm{aOR}^{\mathrm{b}}$ & $95 \% \mathrm{Cl}^{\mathrm{c}}$ \\
\hline \multicolumn{3}{|c|}{ Wearing a fixed orthodontic appliance } \\
\hline Yes & 9.49 & $2.57-35.07$ \\
\hline No & 1.00 & \\
\hline Age d & 1.31 & $0.83-2.07$ \\
\hline \multicolumn{3}{|l|}{ Gender } \\
\hline Female & 0.28 & $0.09-0.87$ \\
\hline Male & 1.00 & \\
\hline \multicolumn{3}{|c|}{ Salivary buffer capacity } \\
\hline Low & 1.11 & $0.14-8.62$ \\
\hline High & 1.00 & \\
\hline $\mathrm{pH} \mathrm{d}$ & 0.69 & $0.09-5.30$ \\
\hline
\end{tabular}

a: Logistic regression model adjusted for all potential predictors reported in the table

b: Adjusted Odds Ratio

c: $95 \%$ Confidence Interval of the aOR

d: aOR per unit increase

\section{RESULTS}

\section{Descriptive analysis}

The study population consisted of 95 children without loss to follow-up, who were divided into two groups. The orthodontic group comprised 48 children (32 females and 16 males, mean age 13.87 years, $S D=1.25)$. The control group comprised 47 children (24 females and 23 males, mean age 13.24 years, $S D=1.21$ ).

At the start of the study, oral health behaviour (frequency of daily tooth-brushing and daily frequency of sugar consumption) and biological parameters (salivary $\mathrm{pH}$, Streptococcus mutans and Lactobacillus spp, and buffer capacity) were similar in the orthodontic and control groups. Differences between the two groups were not statistically significant (Table 1).

\section{Multivariate analysis}

In the multivariate analyses, we found that wearing a fixed orthodontic appliance was an independent risk factor for high levels of Streptococcus mutans (Table 2) and Lactobacillus spp (Table 3) (adjusted OR: 6.65, 95\% CI [1.9822.37]; 9.49, 95\% CI [2.57-35.07], respectively).

\section{DISCUSSION}

A number of studies have investigated the influence of orthodontic therapy and appliances on the oral microbial flora. The originality of the present epidemiological study was to evaluate the evolution of caries risk factors with salivary microbial parameters in a population of children with fixed orthodontic appliances versus a control group of children not receiving orthodontic treatment, during a six-month period. The baseline data for both groups were similar, which was necessary if the two groups were to be usefully compared.

In the orthodontic group, the most remarkable variation at 6 months was a significant increase in the cariogenic microorganisms Streptococcus mutans and Lactobacillus spp. According to Chang, et al. ${ }^{7}$ (1999) the increase in Streptococcus mutans following placement of orthodontic devices can be explained by the irregular nature of their surfaces, which promote the growth of these aciduric and acidogenic bacteria that prefer hard surfaces to grow on. The fixed installation of retentive elements that remain in the mouth for at least 1 or 2 years results in a multiplication of cariogenic microorganisms.

Peros, et al. ${ }^{21}$ (2011) have presented new data on the duration of salivary microbial changes elicited by the placement of fixed orthodontic appliances. In their study ${ }^{23}$, as in some other investigations ${ }^{1,2,11}$, a significant increase in the cariogenic microorganisms Streptococcus mutans and Lactobacillus spp in saliva was found after commencing fixed orthodontic therapy.

In our study, multivariate analysis was performed to observe whether Streptococcus mutans and Lactobacillus spp numbers were significantly different according to the group (orthodontic or control) with adjustment for confounding variables (age, sex, pH and buffer capacity). During the study, statistically significant differences appeared in salivary bacterial levels between the end-ofstudy-period and the baseline data, adjusted for 
other covariables. The purpose of adjustment was to correct the measurement of the effect of orthodontic treatment compared to "noise effects" induced by covariates that could have influenced the outcome. Adjustment increases accuracy by taking account of a factor that increases the variability of outcome. It can also take the effect of confounding factors into account. Only some of the adjustment factors were considered in the present study. It would be interesting to consider other criteria, such as perceived severity of malocclusion, school performance, marital status of the parents or the orthodontic resin used ${ }^{28}$. Al-Jewair, et al. ${ }^{2}$ (2011) showed that compliance with oral hygiene instructions during the orthodontic treatment was better for adolescents with married parents and those reporting good academic performance in school.

According to Peros, et al. ${ }^{21}$ (2011) results, the success of antimicrobial preventive measures for orthodontic patients may be improved by proper timing. Such measures should be applied between weeks 6 and 12 of orthodontic therapy, which is when the number of Streptococcus mutans and Lactobacillus spp increase in the saliva. However, Streptococcus mutans and Lactobacillus sp counts also increase significantly 6 months after the insertion of fixed orthodontic appliances. According to Topaloglu-Ak, et al. ${ }^{27}$ (2011), long-term utilisation of orthodontic appliances may have a negative effect on microbial flora and increase the risk of new carious lesions. In our study, the follow-up lasted 6 months. It would be interesting to evaluate the evolution of these microbial parameters until the end of the orthodontic treatment. Preventive measures should continue until the removal of the orthodontic appliances. Thus, it seems necessary to take action in favour of this population at risk ${ }^{6,16}$. We studied the main bacteria involved in the dental caries process. However, the monitoring of other microbial species, such as Candida albicans ${ }^{27}$, may also be considered. Assessment of caries risk is an important part of dental practice, notably in the prevention of caries pathologies ${ }^{19}$. The global care provided to subjects with fixed orthodontic appliances should take a number of factors into account.

\section{CONCLUSION}

Our results suggest that the oral microflora changed with time in the orthodontic group compared to the control group, with Streptococcus mutans and Lactobacillus spp numbers increasing during the six months of follow-up. During the study, statistically significant differences appeared in salivary bacterial levels between the end-ofstudy-period and the baseline data, adjusted for other covariables (age, sex, $\mathrm{pH}$ and buffer capacity).

\section{ACKNOWLEDGEMENTS}

We thank S. Becker for language revision.

\section{REFERENCES}

1- Ahn SJ, Kho HS, Lee SW, Nahm DS. Roles of salivary proteins on the adherence of oral streptococci to various orthodontic brackets. J Dent Res. 2002;81:411-5.

2- Al-Jewair TS, Suri S, Tompson BD. Predictors of adolescent compliance with oral hygiene instructions during two-arch multibracket fixed orthodontic treatment. Angle Orthod. 2011;81:525-31.

3- Ayo-Yusuf OA, Reddy PS, van Wyk PJ, van den Borne BW. Household smoking as a risk indicator for caries in adolescents' permanent teeth. J Adolesc Health. 2007;41:309-11.

4- Badawi H, Evans RD, Wilson M, Ready D, Noar JH, Pratten J. The effect of orthodontic bonding materials on dental plaque accumulation and composition in vitro. Biomaterials. 2003;24:3345-50.

5- Balenseifen JW, Madonia JV. Study of dental plaque in orthodontic patients. J Dent Res. 1970;49:320-4.

6- Cantekin K, Celikoglu M, Karadas M, Yildirim H, Erdem A. Effects of orthodontic treatment with fixed appliances on oral health status: a comprehensive study. J Dent Sciences. 2011;6:235-8. 7- Chang HS, Walsh LJ, Freer TJ. The effect of orthodontic treatment on salivary flow, $\mathrm{pH}$, buffer capacity, and levels of mutans streptococci and lactobacilli. Aust Orthod J. 1999;15:22934.

8- Corbett JA, Brown LR, Keene HJ, Horton IM. Comparison of Streptococcus mutans concentrations in non-banded and banded orthodontic patients. J Dent Res. 1981;60:1936-42.

9- Ericson D, Bratthall D. Simplified method to estimate salivary buffer capacity. Scand J Dent Res. 1989;97:405-7.

10- Forsberg CM, Brattström V, Malmberg E, Nord CE. Ligature wires and elastomeric rings: two methods of ligation, and their association with microbial colonization of Streptococcus mutans and lactobacilli. Eur J Orthod. 1991;13:416-20.

11- Fournier A, Payant L, Bouclin R. Adherence of Streptococcus mutans to orthodontic brackets. Am J Orthod Dentofacial Orthop. 1998; $114: 414-7$.

12- Germa A, Kaminski M, Nabet C. Impact of social and economic characteristics on orthodontic treatment among children and teenagers in France. Community Dent Oral Epidemiol. 2010;38:171-9.

13- Jensen B, Bratthall D. A new method for the estimation of mutans streptococci in human saliva. J Dent Res. 1989;68:468-71. 14- Källestål C, Fjelddahl A. A four-year cohort study of caries and its risk factors in adolescents with high and low risk at baseline. Swed Dent J. 2007;31:11-25.

15- Kanaya T, Kaneko N, Amaike C, Fukushima M, Morita S, Miyazaki $\mathrm{H}$, et al. The effect of orthodontic appliances on levels of Streptococcus mutans, Streptococcus sobrinus and microbial flora in saliva. Int Congr Ser. 2005;1284:189-90.

16- Karadas M, Cantekin K, Celikoglu M. Effects of orthodontic treatment with a fixed appliance on the caries experience of patients with high and low risk of caries. J Dent Sciences. 2011;6:195-9.

17- Larmas M. A new dip-slide method for the counting of salivary lactobacilli. Proc Finn Dent Soc. 1975;71:31-5.

18- Lundström F, Krasse B. Caries incidence in orthodontic patients with high levels of Streptococcus mutans. Eur J Orthod. 1987;9:117-21.

19- Maltz M, Jardim JJ, Alves LS. Health promotion and dental caries. Braz Oral Res. 2010;24:18-25.

20- Moynihan PJ. The role of diet and nutrition in the etiology and prevention of oral diseases. Bull WHO. 2005;83:694-9. 
21- Peros K, Mestrovic S, Anic-Milosevic S, Slaj M. Salivary microbial and nonmicrobial parameters in children with fixed orthodontic appliances. Angle Orthod. 2011;81:901-6.

22- Proffit WR. Contemporary orthodontics. $4^{\text {th }}$ ed. St. Louis: Mosby Elsevier; 2007.

23- Rosenbloom RG, Tinanoff N. Salivary Streptococcus mutans levels in patients before, during, and after orthodontic treatment. Am J Orthod Dentofacial Orthop. 1991;100:35-7.

24- Sakamaki ST, Bahn AN. Effect of orthodontic banding on localized oral lactobacilli. J Dent Res. 1968;47:275-9.

25- Sanpei S, Endo T, Shimooka S. Caries risk factors in children under treatment with sectional brackets. Angle Orthod. 2010;80:509-14
26- Scheie AA, Arneberg P, Krogstad O. Effect of orthodontic treatment on prevalence of Streptococcus mutans in plaque and saliva. Scand J Dent Res. 1984;92:211-7.

27- Topaloglu-Ak A, Ertugrul F, Eden E, Ates M, Bulut H. Effect of orthodontic appliances on oral microbiota - 6 month follow-up. J Clin Pediatr Dent. 2011;35:433-6.

28- Velazquez-Enriquez U, Scougall-Vilchis RJ, Contreras-Bulnes R, Flores-Estrada J, Uematsu S, Yamaguchi R. Quantitative analysis of $S$. mutans and $S$. sobrinus cultivated independently and adhered to polished orthodontic composite resins. J Appl Oral Sci. 2012;20:544-9.

29- Zickert I, Emilson CG, Krasse B. Correlation of level and duration of Streptococcus mutans infection with incidence of dental caries. Infect Immun. 1983;39:982-5. 